\title{
Impact of stunting on early childhood cognitive development in Benin: evidence from Demographic and Health Survey
}

\author{
Michael Ekholuenetale ${ }^{1 *}$, Amadou Barrow ${ }^{2}$, Charity Ehimwenma Ekholuenetale ${ }^{3}$ and Godson Tudeme ${ }^{4}$
}

\begin{abstract}
Background: Proper nutrition is crucial for enhancing brain function and improving learning. Over time, large evidence has existed to show that childhood undernutrition, marked by stunting, is connected with age-long reduction in cognitive and academic achievement. It is of interest to achieve healthy growth and optimal cognitive development in early childhood. The objective of this study was to examine stunting considered to adversely influence cognitive development among children and therefore of public health importance.

Results: About two thirds (64.3\%) of under-five children attained optimal cognition. Stunted children had 7\% reduction in optimal cognitive development, compared with not stunted children ( $R R=0.93 ; 95 \% \mathrm{Cl} 0.83,0.98)$. Among the covariates, geographical region was significantly associated with optimal cognitive development. In addition, children of Islamic, traditional/other religion, and no religion had significant reduction in optimal cognitive development, compared with children of Christianity belief. Children from mothers who had secondary and tertiary education, listened to radio, and watched television had an increase in optimal cognitive development, compared with children from uneducated mothers. Furthermore, children from mothers who are employed had an $8 \%$ increase in optimal cognitive development ( $R R=1.08 ; 95 \% \mathrm{Cl}: 1.02,1.14)$.

Conclusion: Due to the adverse impact of stunting on optimal cognitive development, we suggest that government and stakeholders in child welfare should ensure that development programmes combine health and nutrition services with early learning and rely on families as partners to have children's cognitive development effectively. Early childhood cognitive development programmes should be implemented through families and caregivers, with special focus on disadvantaged children as a poverty reduction strategy, and ensure that all children are adequately nourished.
\end{abstract}

Keywords: Undernutrition, Hidden hunger, Underweight, Mental health, Childhood

\section{Background}

Cognitive development constitutes a complex and multifaceted set of mental abilities. In children, this process tracks the development of diverse areas such as reasoning, memory, problem-solving, learning, and knowledge representation. Optimal levels of cognitive development are hinged on classical achievements in thinking, language, and understanding as seen in children, specifically

\footnotetext{
* Correspondence: mic42006@gmail.com

'Department of Epidemiology and Medical Statistics, Faculty of Public Health, College of Medicine, University of Ibadan, Ibadan, Nigeria

Full list of author information is available at the end of the article
}

from the well-off settings. Abnormal development can be identified as a shortfall in these optimal gains. Early childhood development programmes that focus on nutrition, health, and education are known to have positive impact on the cognitive development of children from disadvantaged or poor-resource background [1, 2]. Albeit, it is sad to note that more than 200 million children in resource-constrained settings are unable to achieve their optimal level of cognitive development due to poverty and stunting [3].

The rate of childhood malnutrition is worrisome, especially in resource-constrained settings [4]. Malnutrition 
is associated with sub-optimal brain development, which adversely affects cognitive development including educational achievement and economic productivity later in adulthood [5]. The first 1000 days of life is a very critical phase in the life of a child due to the physical and mental development which occur during that period [6]. Stunting is a major indicator of feeding practices among children and associated with deficits in cognitive development and school achievement anywhere in the world [7, 8]. In addition, cognitive development among children is affected by many nutritional factors including breastfeeding [9]. Improved nutritional status remains a prominent modifiable determinant to improve the cognitive development of children [10]. In many poor-resource settings where malnutrition is prevalent, stunting is regarded as a risk factor that negatively affects the ability of children to learn [11]. No doubt, food insecurity is reportedly associated with poor academic achievement of school age children [12, 13]. Children who are under-nourished have higher risk of lower school attendance and likely to score poorly in cognitive tests [14].

Based on the United Nations Children's Fund (UNICEF) conceptual framework, the key aspects necessary to improve quality of life in children are food consumption (nutrition), health, and psychosocial stimulation [15]. Promotion of proper feeding practices is crucial to improve health and development [16]. A reduction in malnutrition among children is paramount to the achievement of the Sustainable Development Goals (SDGs), especially those targeted to end poverty in all its forms everywhere (SDG 1); end hunger, achieve food security and improved nutrition, and promote sustainable agriculture (SDG 2); and ensure healthy lives and promote well-being for all at all ages (SDG 3) [17, 18]. In light of the severe consequences related to childhood malnutrition, governments have endorsed global targets to reduce chronic undernutrition (stunting) by $40 \%$ by 2025 and to reduce and maintain the prevalence of acute undernutrition (wasting) to less than $5 \%$ in children under-5 years [19]. The promotion of proper nutrition including breastfeeding is a key component of child growth mechanisms, as efforts have been made to improve infant and child feeding practices globally, through the International Code of Marketing of Breast-milk Substitutes [20], the Global Strategy for Infant and Young Child Feeding [21] and The Code, the Baby-Friendly Hospital Initiative (BFHI) [22].

Breastfeeding is a major way of preventing childhood undernutrition. An evidence-based study reported that the severity of stunting and underweight decreased as children are exclusive breastfed [23, 24]. Consequently, breastfeeding is associated with good cognitive functions in children [25]. Prominently, better results on intelligence quotient (IQ) tests and other measures of cognitive development have been reported among children who had been breastfed, compared with those who were formula-fed [26].
Several studies have confirmed the existence of an association between breastfeeding duration and child cognition beyond other factors [25, 27-29]. Many of them identified a notable dose-response relationship, with large difference associated with prolonged breastfeeding. The evidence of a positive correlation between breastfeeding and cognitive development in children is highly dependable. Interestingly, this study has become the foremost to examine the impacts of stunting on cognitive development of children under- 5 years in Benin, West Africa.

\section{Methods}

\section{Data source}

A cross-sectional study design involving nationally representative Benin Demographic and Health Survey (BDHS) data was used. Furthermore, data of children born within the 5 years prior to the survey was used with a sample of 6573 children included from BDHS-2017/ 18 survey. The data is available in the public domain and accessed at http://dhsprogram.com/data/availabledatasets.cfm. BDHS was based on a stratified multi-stage cluster sampling technique. Data was collected on vital reproductive health issues via structured intervieweradministered questionnaires. A major component of the data collection is the maternity history, where women were asked about children birth histories. Data from the birth history have been recoded into separate records for individual children listed by the mothers with data on the study variables extracted for analyses. Details of DHS data collection procedure has been reported previously [30].

\section{Study area}

Benin has a total population of 11.48 million people (in 2018) [31], across 12 geographical regions, namely Alibori, Atacora, Atlantique, Borgou, Collines, Couffo, Donga, Littoral, Mono, Quémé, Plateau, and Zou. Spoken languages are French (official), Fon, and Yoruba [32]. The country spans from north to south and a long stretched country in West Africa, located west of Nigeria and east of Togo; it is bordered to the north by Burkina Faso and Niger and in the south by the Bight of Benin, in the Gulf of Guinea, that part of the tropical North Atlantic Ocean which is roughly south of West Africa. Benin's coastline is about $121 \mathrm{~km}$ long, with an average area of $112,622 \mathrm{~km}^{2}$. Benin's former name, until 1975 , was Dahomey. Porto-Novo, a port on an inlet of the Gulf of Guinea is the nation's capital city; the largest city and economic capital is Cotonou.

\section{Outcome variable and scoring procedure}

Cognitive development was measured using a set of 8 items. The items were reported in binary (yes $=1$ vs. no $=0)$. The mean ( \pm standard deviation) score from the 
sum of all items was used as the cut-off for optimal vs. sub-optimal cognition. This method of scoring and dichotomization was used by previous authors [33]. The overall cognitive development was measured from the following composite items: (1) child can identify or name at least 10 letters of alphabet, (2) child can read at least four words, (3) child can identify or name at least 10 numbers, (4) child can pick up small object with two fingers, (5) child follows simple directions, (6) child can perform task independently, (7) child gets along well with other children or adults, and (8) child does not get distracted easily.

\section{Selection and measurement of explanatory variables}

The focal predictor was stunting. It was calculated using the new Child Growth Standards released by the World Health Organization (WHO) on April 27, 2006. The new standards are the result of an intensive study initiated by WHO in 1997 to develop a new international standard for assessing the physical growth nutritional status and motor development in all children from birth to age five. WHO and its principal partner, the United Nations University, undertook a multi-centre growth reference study which is a community-based, multicountry projects involving more than eight thousand children from Brazil, Ghana, India, Norway, Oman, and the USA. $Z$-scores for height-for-age (HAZ), weight-for-age (WAZ), and weight-for-height (WHZ) were calculated using the WHO growth standards [34]. The following standard case-definitions were applied to each record.

\section{Stunting}

Children whose height-for-age $Z$-score (HAZ) is below minus two standard deviations $(-2 \mathrm{SD})$ from the median of the WHO reference population are considered stunted or chronically malnourished. Stunting, an indicator of chronic malnutrition, refers to linear growth retardation and cumulative growth deficits in children. It reflects the failure to grow in stature, which occurs as a result of inadequate nutrition over a longer period. Stunting of children under- 5 years of age is a stronger indicator of hunger and endemic poverty. The selection of this variable was based of the findings from previous studies [35-37].

\section{Control variables}

Underweight: Underweight refers to low weight-for-age, that is, a child is too thin for his/her age. It is defined in terms of standard deviation from median weight-for-age of the reference WHO population. Children whose weight-for-age were below minus two standard deviations (-2 SD) from the reference population median are classified as underweight. The selection of this variable was based of the findings from previous studies [37].
Wasting: This was calculated using weight-for-height. Children that are below minus two standard deviations (-2 SD) from the reference median were considered wasted. The selection of this variable was based of the findings from previous studies [37]. Duration of breastfeeding: This was obtained by the months of breastfeeding based on mothers' self-reported data. The selection of this variable was based of the findings from previous studies [25, 38].

Other variables include birth weight $(\mathrm{kg})$; place of residence: urban vs. rural; geographical region: Alibori, Atacora, Atlantic, Borgou, Collines, Couffo, Donga, Littoral, Mono, Oueme, Plateau, and Zou; birth type: singleton vs. multiple; sex of child: male vs. female; birth order: 1st, 2nd, 3rd, 4th, 5th, and 6th+; child lives with whom: mother/parent vs. stays elsewhere; preceding birth interval: first born, < 24 months, 24-35 months, 36-47 months, 48-83 months, 84 months+; number of children in a household: $1-2,3-4$, and 5+; age of child (months); religion: Christianity, Islam, Traditional and other religion, and no religion; mother's age: 15-19, 20-24, 2529, 30-34, 35-39, 40-44, 45-49; mother's education: no formal education, primary, secondary, and higher; frequency of reading newspaper/listening to radio/watching television: not at all, less than once a week, and at least once a week; mother's marital status: never in union, currently living with a man, and formerly living with a man; and mother's employment status: employed vs. unemployed. In household wealth quintile, for the computation of wealth index, principal components analysis (PCA) was used to assign the wealth indicator weights. This procedure assigned scores and standardized the wealth indicator variables such as water source, sanitation facilities, floor type, wall, roof, radio, electricity, television, refrigerator, cooking fuel, furniture, and number of persons per room. Thereafter, the factor coefficient scores (factor loadings) and $Z$-scores were calculated. Finally, for each household, the indicator values were multiplied by the loadings and summed to produce the household's wealth index value. The standardized Zscore was used to disentangle the overall assigned scores to poorest, poorer, middle, richer, and richest categories [39]. These variables were selected based on previous studies [35, 40-43].

\section{Ethical consideration}

This study was based on an analysis of population-based dataset available in public domain/online with all identifier information removed. The authors communicated with MEASURE DHS/ICF International and permission was granted to download and use the data. The DHS project obtained the required ethical approvals from the relevant research ethics committee in each country before the survey was conducted. Participants were 
informed of the rationale for the surveys, confidentiality of their responses, and that respondents did not need to answer the questions if they do not feel comfortable doing so. Written informed consents were obtained from participants before being allowed in the surveys.

\section{Statistical analysis}

We applied the "svy" module in Stata to account for sampling weights, clustering, and stratification. Percentage and chart were used to report the prevalence of cognitive development. Chi-square bivariate test was used to examine factors associated with cognitive development. Statistically significant factors in the bivariate analysis were included in the regression model. Multivariable $\log$ binomial regression was used to estimate the risk ratios of the indicators of undernutrition and covariates on cognitive development. Log binomial was suitable due to the fact that logistic regression yields an adjusted odds ratio that approximates the adjusted relative risk when outcome is rare, while adjusting for potential confounders. For more common outcomes, the odds ratio always overstates the relative risk [44, 45]. When a study outcome is rare in all strata used for an analysis, the odds ratio estimate of causal impacts will approximate the risk ratio; therefore, odds ratios from most cross-sectional studies can be interpreted as risk ratios. However, if a study outcome is common, the odds ratio will be further from 1 than the risk ratio [46, 47]. Furthermore, risk ratios have a mathematical property called collapsibility; this means that the size of the risk ratio will not change if adjustment is made for a variable that is not a confounder. Because of collapsibility, the risk ratio, assuming no confounding, has a useful interpretation as the ratio change in average risk due to exposure among the exposed. Because odds ratios are not collapsible, they usually lack any interpretation either as the change in average odds or the average change in odds (the average odds ratio). Analyses were conducted using Stata Version 14 (StataCorp 2014). Statistical significance was determined at $p<0.05$.

\section{Results}

Results from Table 1 showed that about two thirds (64.3\%) of children under-5 years attained optimal cognition. The factors that were significantly associated with cognitive development include stunting, underweight, place of residence, region, household quintile, birth order, preceding birth interval, number of children in a household, age of a child, religion, mother's education, frequency of mother's reading newspaper or magazine, listening to radio, watching television, and mother's marital and employment status.

The factors associated with optimal cognitive development were presented in Table 2. Stunted children had
$7 \%$ reduction in optimal cognitive development, compared with children that are not stunted after adjusting for confounders $(\mathrm{RR}=0.93$; 95\%CI $0.83,0.98)$. The geographical region and religiosity were significantly associated with optimal cognitive development. Children of Islam, Traditional/other religion, and no religion had significant reduction in optimal cognitive development, compared with children from Christianity background. The children from mothers who had secondary and tertiary education, listened to radio, and watched television had increase optimal cognitive development, compared with children from non-educated mothers after adjusting for other covariates. Children from mothers who are employed had $8 \%$ increase in cognitive development after adjusting for other confounders ( $\mathrm{RR}=1.08$; $95 \% \mathrm{CI}$ $1.02,1.14)$.

\section{Discussion}

In this study, the magnitude of optimal cognitive development attained by the under-five children was approximately two thirds. Notably, we found significant adverse impacts of stunting on early childhood optimal cognitive development. This finding is consistent with the reports from previous studies [13, 14, 35, 36, 48]. The need for widespread intervention to target early childhood cognitive development for children with undernourishment is confirmed by the findings of this study $[1,49]$. Also, this study provides strong empirical evidence that food insecurity is linked to mental development consequences for children in Benin. Other confounders associated with childhood cognitive development include geographical region. Religious background was also identified in line with previous report on individual parents' religiosity and cognitive development [41], mother's use of media (radio and television), and participation in the labour force were significant covariates. Children whose mothers had secondary and higher education levels were found to have better cognitive development. This is similar to the findings from previous studies [35, 42]. Low educational level in parents limits their ability to promote good cognitive development in their children, which in turn leads to an inter-generational impact.

No doubt, stunted children had sub-optimal cognitive development compared with well-nourished children. A similar study from Nigeria reported stunting to be inversely associated with cognitive development [50]. The long-term implication is that cognitive skills provide the basis for later academic and employment success $[3,51]$. Another previous study reported that nutritional differences provided the strongest explanation for the test performance differences observed in a follow-up between the subjects exposed to different supplements. From that study, food supplementation during the first $2-3$ years of life improved cognition at 3 years of age 
Table 1 The factors associated with under-five cognitive development using Chi-square test

\begin{tabular}{|c|c|c|c|c|}
\hline \multirow[t]{2}{*}{ Variable } & \multirow[t]{2}{*}{$n$} & \multicolumn{2}{|c|}{ Cognitive development } & \multirow[t]{2}{*}{$P$ value } \\
\hline & & Optimal (64.3\%) & Sub-optimal (35.7\%) & \\
\hline Stunting status & & & & $<0.001^{*}$ \\
\hline Stunted & 1914 & $1141(59.6)$ & $773(40.4)$ & \\
\hline Not stunted & 4102 & $2765(67.4)$ & $1337(32.6)$ & \\
\hline Underweight status & & & & $<0.001^{*}$ \\
\hline Underweight & 962 & $562(58.4)$ & $400(41.6)$ & \\
\hline Not underweight & 5068 & $3347(66.0)$ & $1721(34.0)$ & \\
\hline Wasting status & & & & 0.549 \\
\hline Wasted & 286 & $179(62.6)$ & $107(37.4)$ & \\
\hline Not wasted & 5962 & $3835(64.3)$ & $2127(35.7)$ & \\
\hline Duration child was breastfed & & & & 0.761 \\
\hline$<12$ months & 956 & $600(62.8)$ & $356(37.2)$ & \\
\hline 12 months + & 825 & $512(62.1)$ & $313(37.9)$ & \\
\hline Birth weight $(\mathrm{kg})(\text { mean } \pm \text { standard })^{\circledast}$ & 3920 & $3.1 \pm 0.6(n=2755)$ & $3.1 \pm 0.6(n=1165)$ & 0.497 \\
\hline Place of residence & & & & $<0.001^{*}$ \\
\hline Urban & 2547 & $1737(68.2)$ & $810(31.8)$ & \\
\hline Rural & 4026 & $2487(61.8)$ & 1539 (38.2) & \\
\hline Region & & & & $<0.001^{*}$ \\
\hline Alibori & 822 & $388(47.2)$ & $434(52.8)$ & \\
\hline Atacora & 581 & $389(67.0)$ & $192(33.0)$ & \\
\hline Atlantic & 623 & $501(80.4)$ & $122(19.6)$ & \\
\hline Borgou & 903 & $410(45.4)$ & $493(54.6)$ & \\
\hline Collines & 532 & $367(69.0)$ & $165(31.0)$ & \\
\hline Couffo & 443 & $283(63.9)$ & $160(36.1)$ & \\
\hline Donga & 457 & $305(66.7)$ & $152(33.3)$ & \\
\hline Littoral & 392 & $313(79.9)$ & $79(20.1)$ & \\
\hline Mono & 304 & $196(64.5)$ & $108(35.5)$ & \\
\hline Oueme & 519 & $420(80.9)$ & $99(19.1)$ & \\
\hline Plateau & 386 & $224(58.0)$ & $162(42.0)$ & \\
\hline Zou & 611 & $428(70.0)$ & $183(30.0)$ & \\
\hline Household wealth quintile & & & & $<0.001^{*}$ \\
\hline Poorest & 1530 & $842(55.0)$ & $688(45.0)$ & \\
\hline Poorer & 1351 & $844(62.5)$ & $507(37.5)$ & \\
\hline Middle & 1297 & $834(64.3)$ & $463(35.7)$ & \\
\hline Richer & 1217 & $793(65.2)$ & $424(34.8)$ & \\
\hline Richest & 1178 & 911 (77.3) & $267(22.7)$ & \\
\hline Birth type & & & & 0.312 \\
\hline Singleton & 6328 & $4074(64.4)$ & $2254(35.6)$ & \\
\hline Multiple & 245 & $150(61.2)$ & 95 (38.8) & \\
\hline Sex of child & & & & 0.741 \\
\hline Male & 3387 & $2183(64.5)$ & $1204(35.5)$ & \\
\hline Female & 3186 & $2041(64.1)$ & 1145 (35.9) & \\
\hline Birth order & & & & $<0.001^{*}$ \\
\hline $1 \mathrm{st}$ & 826 & $574(69.5)$ & $252(30.5)$ & \\
\hline
\end{tabular}


Table 1 The factors associated with under-five cognitive development using Chi-square test (Continued)

\begin{tabular}{|c|c|c|c|c|}
\hline \multirow[t]{2}{*}{ Variable } & \multirow[t]{2}{*}{$n$} & \multicolumn{2}{|c|}{ Cognitive development } & \multirow[t]{2}{*}{$P$ value } \\
\hline & & Optimal (64.3\%) & Sub-optimal (35.7\%) & \\
\hline 2nd & 1388 & $921(66.4)$ & 467 (33.6) & \\
\hline $3 r d$ & 1226 & $800(65.3)$ & $426(34.7)$ & \\
\hline 4th & 982 & $624(63.5)$ & $358(36.5)$ & \\
\hline 5 th & 738 & $445(60.3)$ & $293(39.7)$ & \\
\hline 6 th + & 1412 & $860(60.9)$ & $552(39.1)$ & \\
\hline Child lives with whom & & & & 0.212 \\
\hline Mother & 6352 & $4089(64.4)$ & $2263(35.6)$ & \\
\hline Stays elsewhere & 9 & $4(44.4)$ & $5(55.6)$ & \\
\hline Preceding birth interval & & & & $<0.001^{*}$ \\
\hline First born & 844 & $586(69.4)$ & $258(30.6)$ & \\
\hline$<24$ months & 925 & $553(59.8)$ & $372(40.2)$ & \\
\hline 24-35 months & 2541 & $1650(64.9)$ & $891(35.1)$ & \\
\hline 36-47 months & 1456 & $903(62.0)$ & $553(38.0)$ & \\
\hline 48-83 months & 697 & $457(65.6)$ & $240(34.4)$ & \\
\hline 84 months + & 110 & $75(68.2)$ & $35(31.8)$ & \\
\hline
\end{tabular}

Number of children in a household

$1-2$

3-4

$5+$

Age (in months) of child (mean \pm standard deviation) in months ${ }^{\circledast}$ Religion

Christianity

Islam

Traditional and other religion

No religion

Mother's age

15-19

20-24

25-29

30-34

35-39

40-44

45-49

Mother's education

No education

Primary

Secondary

Tertiary

Frequency of reading newspaper or magazine by mothers

Not at all

Less than once a week

At least once a week

$2429+1617(66.6)$$$
24
$$

2843

1301

6573

1617 (66.6)

1808 (63.6)

$799(61.4)$

$35.7 \pm 17.7(n=4224)$

3245

2217

718

393

2400 (74.0)

1194 (53.9)

403 (56.1)

227 (57.8)

72

1044

38 (52.8)

$671(64.3)$

2093

1606

1082

476

200

$1340(64.0)$

$1057(65.8)$

686 (63.4)

300 (63.0)

$132(66.0)$

4595

1112

782

84

$\begin{array}{ll}6270 & 3993(63.7) \\ 186 & 141(75.8) \\ 117 & 90(76.9)\end{array}$

$0.005^{*}$

812 (33.4)

1035 (36.4)

$502(38.6)$

$34.7 \pm 17.6(n=2349) \quad 0.032^{*}$

$<0.001^{*}$

845 (26.0)

1023 (46.1)

$315(43.9)$

$166(42.2)$

$34(47.2)$

373 (35.7)

753 (36.0)

549 (34.1)

396 (36.6)

176 (37.0)

68 (34.0)

$<0.001^{*}$

$1826(39.7)$

$338(30.4)$

176 (22.5)

$9(10.7)$

$<0.001^{*}$

2277 (36.3)

$45(24.2)$

27 (23.1)

Frequency of listening to radio by mothers 
Table 1 The factors associated with under-five cognitive development using Chi-square test (Continued)

\begin{tabular}{|c|c|c|c|c|}
\hline \multirow[t]{2}{*}{ Variable } & \multirow[t]{2}{*}{$n$} & \multicolumn{2}{|c|}{ Cognitive development } & \multirow[t]{2}{*}{$P$ value } \\
\hline & & Optimal (64.3\%) & Sub-optimal (35.7\%) & \\
\hline Not at all & 2927 & $1649(56.3)$ & $1278(43.7)$ & \\
\hline Less than once a week & 1392 & $1026(73.7)$ & $366(26.3)$ & \\
\hline At least once a week & 2254 & $1549(68.7)$ & $705(31.3)$ & \\
\hline Frequency of watching television by mothers & & & & $<0.001^{*}$ \\
\hline Not at all & 4376 & $2614(59.7)$ & $1762(40.3)$ & \\
\hline Less than once a week & 752 & $752(71.7)$ & $297(28.3)$ & \\
\hline At least once a week & 858 & $858(74.7)$ & $290(25.3)$ & \\
\hline Mother's marital status & & & & $0.013^{*}$ \\
\hline Never in union & 65 & $51(78.5)$ & $14(21.5)$ & \\
\hline Currently in union/living with a man & 6303 & $4030(63.9)$ & $2273(36.1)$ & \\
\hline Formerly in union/living with a man & 205 & $143(69.8)$ & $62(30.2)$ & \\
\hline Mother's employment status & & & & $<0.001^{*}$ \\
\hline Employed & 5547 & $3648(65.7)$ & $1899(34.2)$ & \\
\hline Unemployed & 1026 & $576(56.1)$ & $450(43.9)$ & \\
\hline
\end{tabular}

*Significant at $p<0.05$

and beyond [52]. A prominent approach to prevent stunting in early childhood is exclusive breastfeeding [53]. The inter-connectivity between exclusive breastfeeding and stunting reduction and hence improved cognitive development could be the best explanation for an experimental study which showed an improvement in motor development with exclusive breastfeeding [54]. On the other hand, another study in a long follow-up duration identified supplementation before age 3 years to have beneficial impacts on reading, schooling, and intelligence tests later in adulthood [55]. Now, there is a large and increasing body of evidence to indicate that nutrition affect children's cognitive development.

Specifically, nutritional status based on the height index for age has a significant and positive impacts on cognitive development of children [37]. This could have a direct impact on children's central nervous systems. Worst still, stunted children have multiple functional disadvantages that can persist throughout their lifetime. The poor cognitive development and educational level of stunted children could limit economic productivity, particularly in individual adults and the nation at large. The exact mechanism connecting stunting to sub-optimal mental development is yet to be known. However, it is possible that the mechanism varies according to the nutrients that are lacking or that many assumed mechanisms could act differently or unanimously. A prominent assumption is that undernutrition causes poor motor development and consequently low activity levels. More so, it could cause lack of interest in the environment and social interaction. Thus, children explore their environment less and fail to gain skills at the proper pace [56].

Inequalities in socioeconomic status such as maternal education could be another major explanation to childhood cognitive development. When it comes to children knowing their right to survive or develop, the odds are stacked against the most disadvantaged. Such children would encounter diminished prospects of optimal development because the conditions of birth are grossly filled with inequities. Unfortunately, this really is costly in the social, human, economic, and political world. Therefore, sustainable progress for children requires a focus on equity. Reaching the most marginalized children is of great importance and required to meet the 2030 goals on child health and well-being [57]. Undernutrition is rarely regarded as an emergency; the children affected are not facing famine and present very few or no obvious signs. Still, the largely hidden crisis of undernutrition is implicated in more than half of all child deaths globally and violates children's rights in several ways, compromising their physical and mental development and helping to sustain poverty. Undernutrition is more widespread than many people think with approximately one third of children been affected and hence reduces the productivity of the societies in general [15].

\section{Strength and limitation}

A major strength of this study is the use of nationally representative data set. The findings can also be used to make plausible generalizability. Over the past decades, there was a dearth of appropriate tools with which to 
Table 2 Multivariable log binomial model of the factors associated with optimal cognitive development

Variable

Stunted

Underweight status (ref: not underweight)

$$
\text { Underweight }
$$

Residence (ref: urban)

Rural

Region (ref: Alibori)

Atacora
Atlantic
Borgou
Collines
Couffo
Donga
Littoral
Mono
Oueme
Plateau
Zou

Household wealth quintile (ref: poorest)

$\begin{array}{ll}\text { Poorer } & 1.01 \\ \text { Middle } & 1.00 \\ \text { Richer } & 0.96 \\ \text { Richest } & 0.98\end{array}$

Birth order (ref: 1st)

2nd
3 rd
4 th
5 th
6 th +

Preceding birth interval (ref: first born)

$$
\begin{aligned}
& <24 \text { months } \\
& 24-35 \text { months } \\
& 36-47 \text { months } \\
& \text { 48-83 months } \\
& 84 \text { months }+
\end{aligned}
$$

Age of child

\section{Religion (ref: Christianity)}

Islam

Traditional and other religion

No religion

Mother's education (ref: no education)

$$
\begin{aligned}
& \text { Primary } \\
& \text { Secondary } \\
& \text { Tertiary }
\end{aligned}
$$$$
1.01
$$

Risk Ratio

0.93

0.98

.03

(n)

92

0.95

0.99

3

07

.00

\section{5\%Cl}

$0.89,0.98$

$0.92,1.04$

$0.98,1.07$

0.241

$<0.001^{*}$

$<0.001^{*}$

0.274

$<0.001^{*}$

$<0.001^{*}$

$<0.001^{*}$

$<0.001^{*}$

$<0.001^{*}$

$<0.001^{*}$

0.108

$<0.001^{*}$

$1.17,1.44$

0.95, 1.07

0.737

0.887

0.217

0.589

$0.91,1.06$

$0.69,1.30$

0.740

$0.68,1.29$

0.688

$0.67,1.27$

0.613

0.624

0.740

$0.68,1.31$

$0.72,1.37$

0.969

$0.75,1.43$

0.816

$0.75,1.42$

0.870

$0.78,1.48$

0.670

$0.74,1.45$

0.849

$0.99,1.01$

0.072

$0.88,0.98$

$0.012^{*}$

$0.74,0.85$

$<0.001^{*}$

$0.012^{*}$

$0.81,0.97$

0.660

$0.97,1.06$

$0.004^{*}$

$1.02,1.14$

$1.10,1.39$

$<0.001^{*}$ 
Table 2 Multivariable log binomial model of the factors associated with optimal cognitive development (Continued)

\begin{tabular}{|c|c|c|c|}
\hline Variable & Risk Ratio & $95 \% \mathrm{Cl}$ & $P$ \\
\hline \multicolumn{4}{|c|}{ Frequency of reading newspaper or magazine by mothers (ref: not at all) } \\
\hline Less than once a week & 0.96 & $0.89,1.04$ & 0.328 \\
\hline At least once a week & 0.98 & $0.87,1.09$ & 0.656 \\
\hline \multicolumn{4}{|c|}{ Frequency of listening to radio by mothers (ref: not at all) } \\
\hline Less than once a week & 1.16 & $1.10,1.22$ & $<0.001^{*}$ \\
\hline At least once a week & 1.05 & $1.00,1.10$ & $0.045^{*}$ \\
\hline \multicolumn{4}{|c|}{ Frequency of watching television by mothers (ref: not at all) } \\
\hline Less than once a week & 1.06 & $1.02,1.11$ & $0.010^{*}$ \\
\hline At least once a week & 1.11 & $1.06,1.17$ & $<0.001^{*}$ \\
\hline \multicolumn{4}{|l|}{ Mother's marital status (never in union) } \\
\hline Currently in union/living with a man & 1.06 & $0.91,1.23$ & 0.436 \\
\hline Formerly in union/living with a man & 1.05 & $0.89,1.23$ & 0.565 \\
\hline \multicolumn{4}{|c|}{ Mother's employment status (unemployed) } \\
\hline Employed & 1.08 & $1.02,1.14$ & $0.010^{*}$ \\
\hline
\end{tabular}

*Significant at $p<0.05$

assess cognitive development in very young children and there were no globally accepted tests of early cognitive development. Interestingly, BDHS has provided a set of proxy composite items to measure childhood cognitive development. However, it would have been important to evaluate social and emotional development as well, because these factors may be equally, if not more, important to an individual's cognitive success in life. Another drawback in this study is the use of cross-section data which is not sufficient to establish causality.

\section{Conclusion}

Based on our findings, critical policy insights can be deduced. These insights will enable policy-makers and public health researchers to develop effective nutrition and education interventions that will involve community-adapted strategies targeted at improving the well-being and development of children. Social protection and poverty alleviation programmes such as child support and agricultural improvement schemes are also needed to improve food security. In a country where stunting is prevalent, there is need to develop programmes to improve children's nutritional status such as school feeding. Such programmes will perhaps be most effective if they are instituted among children in the first 5 years of life and are integrated with child care and psychosocial interventions. In addition, programmes targeting to address stunting should span across multiple ministries such as health, education, and welfare. Growth monitoring surveillance will also have added advantage for child development.

Due to the adverse impact of stunting on cognitive development, we suggest that government and stakeholders in child welfare should (1) create coordinating mechanisms for ministries that share the responsibility for early childhood development; (2) ensure that development programmes combine health and nutrition services with early learning and rely on families as partners and have adequate quality, intensity, and duration to affect children's cognitive development cost effectively; (3) ensure that all children are adequately nourished, including micronutrients, such as iodine and iron; (4) incorporate early child cognitive development into existing services and systems to increase programme coverage; (5) increase advocacy on the importance of early child cognitive development and the consequences of the loss of developmental potential to individuals and to society at large; (6) implement early child cognitive development interventions through families and caregivers, with special focus on disadvantaged children as a poverty reduction strategy.

\section{Abbreviations}

BDHS: Benin Demographic and Health Survey; BFHI: Baby-Friendly Hospital Initiative; HAZ: Z-score for height-for-age; ICF: Inner City Fund; IQ: Intelligence quotient; RR: Risk ratio; SDGs: Sustainable Development Goals;

UNICEF: United Nations Children's Fund; WAZ: Z-score for weight-for-age;

WHO: World Health Organization; WHZ: Z-score for weight-for-height

\section{Acknowledgements}

The authors appreciate the MEASURE DHS project for the approval and access to the original data.

\section{Authors' contributions}

ME conceived and designed the study, performed data analysis, wrote the results and discussed the findings. $A B, C E E$, and $G T$ contributed to the review of literature and discussed the findings. All authors have read and approved the manuscript. ME had the final responsibility to submit the manuscript.

\section{Funding}

This research received no grant from any funding agency in the public, commercial, or not-for-profit sectors. 


\section{Availability of data and materials}

Data for this study were sourced from Demographic and Health Surveys (DHS) and available at http://dhsprogram.com/data/available-datasets.cfm.

\section{Competing interest}

The authors declare that the research was conducted in the absence of any commercial or financial relationships that could be construed as a potential conflict of interest.

\section{Ethics approval and consent to participate}

Ethics approval for this study was not required since the authors used secondary data available in the public domain. This is not applicable in this study. More details regarding DHS data and ethical standards are available at http://dhsprogram.com/data/available-datasets.cfm.

\section{Consent for publication}

Demographic and Health Survey is a de-identified open-source dataset.

Therefore, the requirement of consent for publication is not applicable.

\section{Author details}

'Department of Epidemiology and Medical Statistics, Faculty of Public Health, College of Medicine, University of Ibadan, Ibadan, Nigeria. ${ }^{2}$ Department of Public \& Environmental Health, School of Medicine \& Allied Health Sciences, University of The Gambia, Kanifing, The Gambia. ${ }^{3}$ Department of Economics, Faculty of Social Sciences, Benin Study Center, National Open University of Nigeria, Benin City, Nigeria. ${ }^{4}$ School of Medicine, College of Medical Sciences, University of Benin, Benin City, Nigeria.

\section{Received: 18 March 2020 Accepted: 9 September 2020}

\section{Published online: 05 October 2020}

\section{References}

1. Engle PL, Black MM, Behrman JR, Cabral de Mello M, Gertler PJ, Kapiriri L, et al. Strategies to avoid the loss of developmental potential in more than 200 million children in the developing world. Lancet. 2007:369(9557):229-242.

2. Nores M, Barnett WS (2010) Benefits of early childhood interventions across the world: (Under) investing in the very young. Econ Educ Rev 29(2):271-282

3. Grantham-McGregor S, Cheung YB, Cueto S, Glewwe P, Richter L, Strupp B (2007) Developmental potential in the first 5 years for children in developing countries. Lancet. 369(9555):60-70

4. Akombi BJ, Agho KE, Merom D, Renzaho AM, Hall JJ (2017) Child malnutrition in sub-Saharan Africa: a meta-analysis of demographic and health surveys (2006-2016). Wieringa F, editor. PLoS ONE 12(5):e0177338

5. Leroy JL, Ruel M, Habicht J-P, Frongillo EA (2014) Linear growth deficit continues to accumulate beyond the first 1000 days in low- and middleincome countries: global evidence from 51 national surveys. J Nutr 144(9): $1460-1466$

6. de Onis M, Branca F (2016) Childhood stunting: a global perspective. Matern Child Nutr 12(Suppl Suppl 1):12-26

7. Daniels MC, Adair LS (2004) Growth in young filipino children predicts schooling trajectories through high school. J Nutr 134(6):1439-1446

8. Walker SP, Chang SM, Powell CA, Simonoff E, Grantham-McGregor SM (2007) Early childhood stunting is associated with poor psychological functioning in late adolescence and effects are reduced by psychosocial stimulation. J Nutr 137(11):2464-2469

9. Zaini MZA, Lim CT, Low WY, Harun F (2005) Effects of nutritional status on academic performance of Malaysian primary school children. Asia Pac J Public Health 17(2):81-87

10. Haile D, Nigatu D, Gashaw K, Demelash H. Height for age z score and cognitive function are associated with academic performance among school children aged 8-11 years old. Arch Public Health. 2016[cited 2019 May 4];74(1). Available from: http://archpublichealth.biomedcentral.com/ articles/10.1186/s13690-016-0129-9

11. Galal O, Hulett J (2003) The relationship between nutrition and children's educational performance: a focus on the United Arab Emirates. Nutr Bull 28(1):11-20

12. Frongillo EA, Jyoti DF, Jones SJ (2006) Food Stamp Program participation is associated with better academic learning among school children. J Nutr 136(4):1077-1080
13. Jyoti DF, Frongillo EA, Jones SJ (2005) Food insecurity affects school children's academic performance, weight gain, and social skills. J Nutr 135(12):2831-2839

14. Alaimo K, Olson CM, Frongillo EA (2001) Food insufficiency and American school-aged children's cognitive, academic, and psychosocial development. Pediatrics. 108(1):44-53

15. Bellamy C, Unicef (1998) The state of the world's children. UNICEF, New York

16. World Health Organization (WHO) (2008) Indicators for assessing infant and young child feeding practices: conclusions of a consensus meeting held 6-8 November 2007 in Washington D.C., USA. World Health Organization (WHO), Washington, D.C

17. Rosa W. Transforming Our World: The 2030 Agenda for Sustainable Development. In: A new era in global health [Internet]. New York, NY: Springer Publishing Company; 2017 [cited 2019 Feb 14]. Available from: http://connect.springerpub.com/lookup/doi/10.1891/9780826190123.ap02

18. Kumar S, Kumar N, Vivekadhish S (2016) Millennium Development Goals (MDGs) to Sustainable Development Goals (SDGs): addressing unfinished agenda and strengthening sustainable development and partnership. Indian J Comm Med 41(1):1

19. de Onis M, Dewey KG, Borghi E, Onyango AW, Blössner M, Daelmans B et al (2013) The World Health Organization's global target for reducing childhood stunting by 2025: rationale and proposed actions. Matern Child Nutr 9(Suppl 2):6-26

20. World Health Organization (1981) International code of marketing of breastmilk substitutes. World Health Organization; Obtainable from WHO Publications Centre, Geneva: Albany, p 36

21. WHO. Global strategy for infant and young child feeding. 2003 [cited 2019 Feb 15]; Available from: www.ennonline.net/globalstrategyiycfarticle

22. World Health Organization, UNICEF. Baby-friendly hospital initiative: revised, updated and expanded for integrated care. 2009 [cited 2019 Feb 15]. Available from: http://www.ncbi.nlm.nih.gov/books/NBK153471/

23. Kumar A, Singh VK (2015) A study of exclusive breastfeeding and its impact on nutritional status of child in EAG states. 3:11

24. Khan MdN, Islam MM. Effect of exclusive breastfeeding on selected adverse health and nutritional outcomes: a nationally representative study. BMC Public Health. 2017 [cited 2020 Mar 10];17. Available from: https://www.ncbi. nlm.nih.gov/pmc/articles/PMC5697409/

25. Boucher O, Julvez J, Guxens M, Arranz E, Ibarluzea J, Sánchez de Miguel M et al (2017) Association between breastfeeding duration and cognitive development, autistic traits and ADHD symptoms: a multicenter study in Spain. Pediatr Res 81(3):434-442

26. Kramer MS, Aboud F, Mironova E, Vanilovich I, Platt RW, Matush L et al (2008) Breastfeeding and child cognitive development: new evidence from a large randomized trial. Arch Gen Psychiatry 65(5):578-584

27. Angelsen NK (2001) Breast feeding and cognitive development at age 1 and 5 years. Arch Dis Child 85(3):183-188

28. Belfort MB, Rifas-Shiman SL, Kleinman KP, Guthrie LB, Bellinger DC, Taveras EM et al (2013) Infant feeding and childhood cognition at ages 3 and 7 years: effects of breastfeeding duration and exclusivity. JAMA Pediatr 167(9): 836-844

29. Quigley MA, Hockley C, Carson C, Kelly Y, Renfrew MJ, Sacker A (2012) Breastfeeding is associated with improved child cognitive development: a population-based cohort study. J Pediatr 160(1):25-32

30. Corsi DJ, Neuman M, Finlay JE, Subramanian S (2012) Demographic and health surveys: a profile. Int J Epidemiol 41(6):1602-1613

31. Worldbank. Population, total - Benin | Data [Internet]. [cited 2020 Mar 28]. Available from: https://data.worldbank.org/indicator/SP.POP.TOTL?locations=B」

32. Republic of Benin - Country Profile. Benin - Country Profile - Nations Online Project. [cited 2019 Dec 13]. Available from: http://www.nationsonline.org/ oneworld/benin.htm

33. Faust L, Yaya S, Ekholuenetale M (2017) Wealth inequality as a predictor of HIV-related knowledge in Nigeria. BMJ Glob Health 2(4):e000461

34. WHO MULTICENTRE GROWTH REFERENCE STUDY GROUP, Onis M (2007) WHO child growth standards based on length/height, weight and age: WHO child growth standards. Acta Paediatr 95:76-85

35. Crookston BT, Dearden KA, Alder SC, Porucznik CA, Stanford JB, Merrill RM et al (2011) Impact of early and concurrent stunting on cognition. Maternal Child Nutr 7(4):397-409

36. Li C, Zhu N, Zeng L, Dang S, Zhou J, Yan H. Effect of prenatal and postnatal malnutrition on intellectual functioning in early school-aged children in 
rural western China. Medicine (Baltimore). 20167 [cited 2019 May 4];95(31). Available from: https:/www.ncbi.nlm.nih.gov/pmc/articles/PMC4979774/

37. Warsito O, Khomsan A, Hernawati N, Anwar F (2012) Relationship between nutritional status, psychosocial stimulation, and cognitive development in preschool children in Indonesia. Nutr Res Pract 6(5):451-457

38. Lee H, Park H, Ha E, Hong Y-C, Ha M, Park H et al (2016) Effect of breastfeeding duration on cognitive development in infants: 3-year followup study. J Korean Med Sci 31(4):579-584

39. Rutstein SO, Staveteig S. Making the demographic and health surveys wealth index comparable. 2014; DHS Methodological Reports No. 9. Rockville, Maryland, USA: ICF International.

40. Ardila A, Rosselli M, Matute E, Inozemtseva O (2011) Gender differences in cognitive development. Dev Psychol 47(4):984-990

41. Bartkowski JP, Xu X, Levin ML (2008) Religion and child development: evidence from the early childhood longitudinal study. Soc Sci Res 37(1):18-36

42. Crookston BT, Forste R, Mc Clellan C, Georgiadis A, Heaton TB. Factors associated with cognitive achievement in late childhood and adolescence: the Young Lives cohort study of children in Ethiopia, India, Peru, and Vietnam. BMC Pediatr. 2014 Dec [cited 2019 Jun 1];14(1). Available from: http://bmcpediatr.biomedcentral.com/articles/10.1186/1471-2431-14-253

43. Feldman R, Eidelman Al (2005) Does a triplet birth pose a special risk for infant development? Assessing cognitive development in relation to intrauterine growth and mother-infant interaction across the first 2 years. Pediatrics. 115(2):443-452

44. Cook TD (2002) Advanced statistics: up with odds ratios! A case for odds ratios when outcomes are common. Acad Emerg Med 9(12):1430-1434

45. McNutt L-A, Wu C, Xue X, Hafner JP (2003) Estimating the relative risk in cohort studies and clinical trials of common outcomes. Am J Epidemiol 157(10):940-943

46. Altman DG, Deeks JJ, Sackett DL (1998) Odds ratios should be avoided when events are common. BMJ. 317(7168):1318

47. Cummings $P$ (2009) The relative merits of risk ratios and odds ratios. Arch Pediatr Adolesc Med 163(5):438-445

48. Kamath SM, Venkatappa KG, Sparshadeep EM (2017) Impact of nutritional status on cognition in institutionalized orphans: a pilot study. J Clin Diagn Res 11(3):CC01-CCO4

49. Nair MKC, Radhakrishnan SR (2004) Early childhood development in deprived urban settlements. Indian Pediatr 41(3):227-237

50. Onifade OM, Otegbayo JA, Akinyemi JO, Oyedele TA, Akinlade AR. Nutritional status as a determinant of cognitive development among preschool children in South-Western Nigeria. Br Food J. 2016 [cited 2019 May 4]; Available from: https://www.emeraldinsight.com/doi/abs/10.1108/ BFJ-11-2015-0445

51. Berlinski S, Galiani S, Gertler P (2009) The effect of pre-primary education on primary school performance. J Public Econ 93(1):219-234

52. Pollitt E, Gorman KS, Engle PL, Martorell R, Rivera J (1993) Early supplementary feeding and cognition: effects over two decades. Monogr Soc Res Child Dev 58(7):1-99 discussion 111-118

53. Kuchenbecker J, Jordan I, Reinbott A, Herrmann J, Jeremias T, Kennedy G et al (2015) Exclusive breastfeeding and its effect on growth of Malawian infants: results from a cross-sectional study. Paediatr Int Child Health 35(1): 14-23

54. Dewey KG, Cohen RJ, Brown KH, Rivera LL (2001) Effects of exclusive breastfeeding for four versus six months on maternal nutritional status and infant motor development: results of two randomized trials in Honduras. J Nutr 131(2):262-267

55. Maluccio JA, Hoddinott J, Behrman JR, Martorell R, Quisumbing AR, Stein $A D$. The impact of nutrition during early childhood on education among Guatemalan adults. SSRN Electron J. 2006 [cited 2019 May 31]; Available from: http://www.ssin.com/abstract=946107

56. Grantham-MCGregor SM, Fernald LC, Sethuraman K (1999) Effects of health and nutrition on cognitive and behavioural development in children in the first three years of life: Part 1: low birthweight, breastfeeding, and proteinenergy malnutrition. Food Nutr Bull 20(1):53-75

57. Watkins K (2016) A fair chance for every child. UNICEF, New York, p 172 (The state of the world's children)

\section{Publisher's Note}

Springer Nature remains neutral with regard to jurisdictional claims in published maps and institutional affiliations.

\section{Submit your manuscript to a SpringerOpen ${ }^{\circ}$ journal and benefit from:}

- Convenient online submission

- Rigorous peer review

- Open access: articles freely available online

- High visibility within the field

- Retaining the copyright to your article

Submit your next manuscript at $\boldsymbol{\nabla}$ springeropen.com 